\title{
A Study of Meat Freshness Detection using Embedded-based pH Sensor
}

\author{
Rajina R. Mohamed ${ }^{1}$, Razali Yaacob², Mohamad A. Mohamed ${ }^{3}$, Arniyati Ahmad ${ }^{4}$, Munir Tajuddin 5 \\ ${ }^{1,5}$ College of Computer Science and Information Technology, Universiti Tenaga Nasional, Malaysia \\ ${ }^{2}$ Faculty of Computer Science and Information Technology, Universiti Putra Malaysia, Malaysia \\ ${ }^{3}$ Faculty of Informatics and Computing, Universiti Sultan Zainal Abidin, Besut Campus, Malaysia \\ ${ }^{4}$ Faculty Science and Technology Defence, Universiti Pertahanan Malaysia, Sg. Besi Camp, Malaysia
}

\begin{tabular}{l}
\hline \hline Article Info \\
\hline Article history: \\
Received Sep 12, 2018 \\
Revised Nov 1, 2018 \\
Accepted Nov 7, 2018 \\
\hline
\end{tabular}

Keywords:

Acidity

Food Poisoning

Food Safety

Meat Freshness

$\mathrm{pH}$ level

\begin{abstract}
For the past few years, food safety incidents often occur as a result of food poisoning from various food sources such as in schools, hospitals, night markets, street stalls and the like. When the quality of food is reduced due to the low level of freshness, cleanliness factor, safety and nutrition, it can contribute to health risks. According to World Health Organization, food poisoning ailment is a global problem and almost 1 in 10 people fall ill every year from eating degraded food and 420000 die as a result. Factors such as cost savings, low awareness on food freshness and busy routine lifestyle aggravate the food poisoning problem. Hence it is important to at least maintain the freshness of the food mainly at the prominent area such as school and hospital. There are many methods used to test the freshness food, such as visual appearance, and also classical olfaction including normal olfactory and Scentometer, which requires trained panels to taste or smell the food samples to ensure the quality or strength of the odor. However, this method is rather subjective, because the human sense of smell and taste is different and may be influenced by the weather and experience. Conventional $\mathrm{pH}$ and litmus paper also are the alternatives, however the material itself is easily damaged and not suitable for the color blind person. In this paper, we presented raw meat examination using $\mathrm{pH}$ sensor based on food acidity. Examination of food freshness level is much easier using $\mathrm{pH}$ sensor since it is more practical to be used by consumers at home since it can be mobile, long lived, and accurate embedded-based application. Some testing has been conducted on sensor capability reacting with several buffer solutions on meat samples left at room temperature at various periods of time. Generally, the embedded $\mathrm{pH}$ sensor developed has successfully tested raw meat freshness level based on acidity level of meat.
\end{abstract}

Copyright $\odot 2018$ Institute of Advanced Engineering and Science. All rights reserved.

\section{Corresponding Author:}

Rajina R. Mohamed,

College of Computer Science and Information Technology,

Universiti Tenaga Nasional, Malaysia.

Email: rajina@uniten.edu.my

\section{INTRODUCTION}

Food is an important source of nutrients for the human body. Thus intake of nutritious, clean and fresh food is essential to the human body. Less hygiene and less nutrition of food intake affect human health [1]. For the busy city folks, sometimes they do not have time to prepare their own meals at home, so they have to buy them out either in stores or fast food restaurant. Buyers do not have time to examine whether the food sources were clean or not. Moreover some food had been prepared earlier. Sometimes leftover food is kept for next meal either due to cost saving or too tired to take the meal. Surely, the meal is kept in the freezer hours before it is savor the next day. Hence, the food freshness is diminishing or become 
stale or fully spoiled the next day. Because of that reason, food poisoning happens due to taking spoiled or stale food. However, factors such as cost savings, low awareness on food freshness and busy routine lifestyle aggravate the food poisoning problem. Hence, there must be some form of food indicator to ensure the freshness level of food to improve the situation at hand.

According to World Health Organization [2], food poisoning ailment is a global problem and almost 1 in 10 people fall ill every year from eating spoiled food and 420000 die as a result. Hence, it is very crucial to test food freshness to resolve or at least to lessen food poisoning cases. In this paper, we presented raw meat examination using $\mathrm{pH}$ sensor based on food acidity. Examination of food freshness level is much easier using $\mathrm{pH}$ sensor since it is more practical to be used by consumers at home. Examination using $\mathrm{pH}$ sensor is done through mobile, long lived, and accurate embedded-based application. There are numerous techniques on food freshness indicator done previously, however most of them are only suitable for research and laboratory conditions. Conventional $\mathrm{pH}$ paper used in prior work is easily damaged and not suitable for the color blind person. RFID-based method to test meat freshness has also been implemented by [3] however RFID tag manipulate electromagnetic spectrum, so they are easily jam, consume more power and sensitive to wet things or liquid matter. Electronic nose is widely used to test food freshness [4-6] however, it is only practical to be used on large amount of food, plus consumers must have some level of knowledge on gas sensors, and furthermore market-ready electric nose is expensive and usage is limited by the different type of gases employed. Hence, food freshness using $\mathrm{pH}$ sensors may more practical especially for consumers at home due to its small size and ease of use. In this paper, we describe the preliminary development of food freshness test using $\mathrm{pH}$ sensor as well as data collection, testing and validation process.

The organization of this paper is as follows, section 2 is about literature studies and related research works, section 3 is on developmental work, section 4 is on testing and validation and lastly section 5 is the conclusion.

\section{LITERATURE REVIEWS}

Meat is a main protein source needed by our body but meat is perishable and easily damaged [7-8], [10]. It must be taken or cooked immediately or freeze or treated as to preserve. Based on few studies done, $\mathrm{pH}$ level is the main factor to indicate the level of meat freshness [9] other than using the obvious color and water contents factor [10]. In fact, factors such as $\mathrm{pH}$, color, water-holding capacity as well as intramuscular fat is used to grade meat quality for exports [11-13]. Based on literature studies, $\mathrm{pH}$ is the most important factor in determining the meat quality. There are many researches done previously using $\mathrm{pH}$ method to test meat quality such as [14] that is using a simple sticker sensor based on litmus paper to detect freshness on beef sample. However, litmus paper will only give binary answers either acidic or alkaline without taking into consideration that the meat might be too alkaline or too acidic. Therefore, freshness test based on $\mathrm{pH}$ scale is better because $\mathrm{pH}$ can be classified according to the acidic and alkaline degree.

According to [9], the ultimate $\mathrm{pH}$ value of high quality meat is at the range of 5.4 - 5.6. In general, un-slaughtered animal has $\mathrm{pH}$ value of 7.1. The transformation of glycogen to lactic acid after slaughtering is due to several factors such as animal type and animal treatment before slaughtering. This will cause a low meat $\mathrm{pH}$ value and ultimately lowering to the level of 5.4 - 5.6 after 18-24 hours slaughtering. When the $\mathrm{pH}$ increases to 6.5 , the meat starts to decompose [15].

A $\mathrm{pH}$ sensor is able to detect $\mathrm{pH}$ value of a specimen based on hydrogen $(\mathrm{H})$ ion concentration commonly in a range of 1 and $10 \times-14$ gram-equivalents per liter [16]. The higher the hydrogen, the higher the acidity of the substance. Basically, the $\mathrm{pH}$ value of a neutral solution is 7.0. Solutions with a $\mathrm{pH}$ value below 7.0 are considered acidic and solutions with $\mathrm{pH}$ value above 7.0 are basic (alkaline). This device will detect $\mathrm{pH}$ value to determine either the meat is fresh or not. The hypothesis is the $\mathrm{pH}$ sensor able to detect $\mathrm{pH}$ value of meat in order to determine its freshness. By using this $\mathrm{pH}$ sensor, the information gathered by the sensor will be sent as the value of output to the microcontroller and the component will operate to communicate with the light emitting diode in order to display the $\mathrm{pH}$ reading.

\section{MEAT FRESHNESS DETECTION SYSTEM}

Meat Freshness Detector is an embedded-based application that help in determining the freshness based on $\mathrm{pH}$ level using a ready-market $\mathrm{pH}$ sensor. This system consists of Arduino microcontroller, $\mathrm{pH}$ sensor, a set of light emitting diode (LED) and switches. The microcontroller is core of the application to receive input from the $\mathrm{pH}$ sensors and send the signal to a dedicated LED to show the output. The microcontroller is programmed using Arduino programming. For this application, $\mathrm{pH}$ sensor has been chosen to have as the range of the indicator from 0.00 until 14.0. The decimal places that can be catered by the sensor is small so any small differences of $\mathrm{pH}$ value can be accepted. 


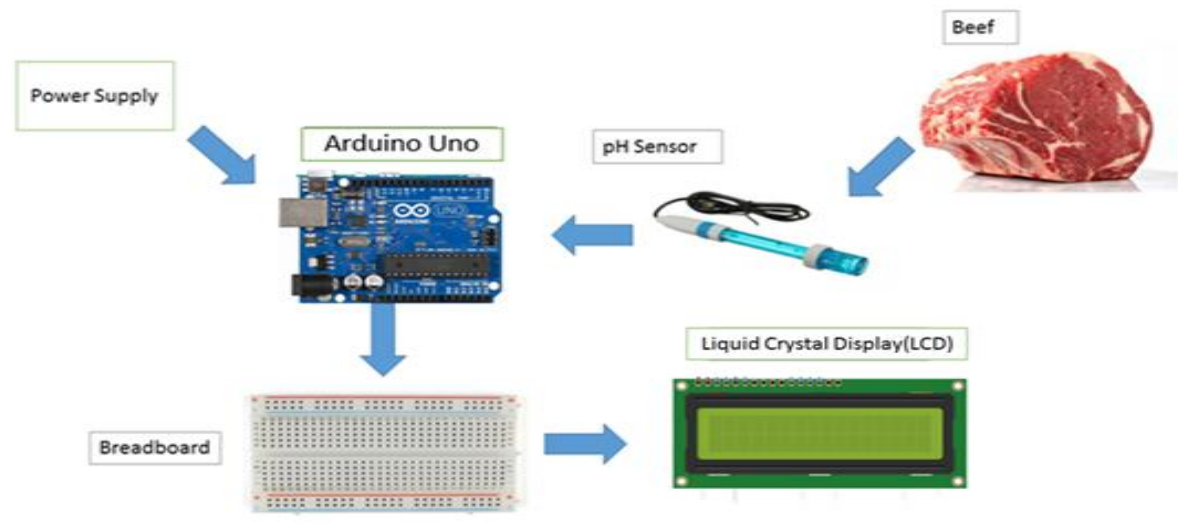

Figure 1. The Component of the Meat Freshness Detection of the Proposed Study

System is executed by integrating all the required components as shown in Figure 1 and interconnected them using Arduino programming. Figure 2 shows the final setup of the prototype.

Based on literature studies done, ultimate $\mathrm{pH}$ value for meat is between 5.4 to $+(-5.7)$. So we set the two threshold here that is 5.8 and 6.2. If the reading shows less than 5.7, then it is acidic which is considered as not ideal or not fresh, while if the reading is more than 6.2 then it is considered above ideal or really fresh, and for the reading between 5.7 and 6.2, it is considered that meat is ideal and fresh. Flowchart in Figure 3 shows how meat freshness detection system works.

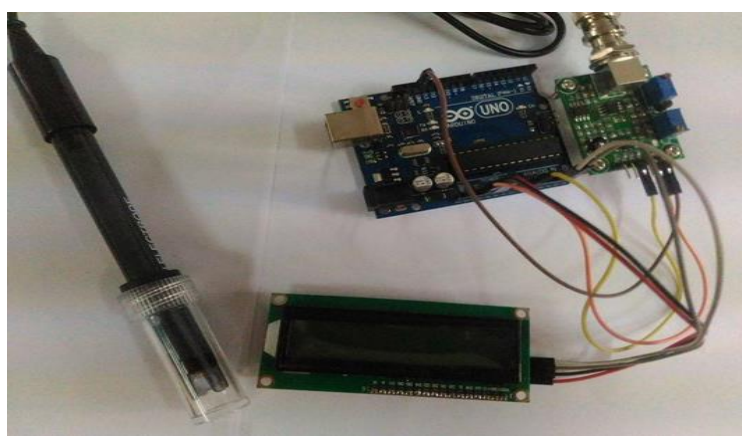

Figure 2. The Complete Setup of the Proposed System

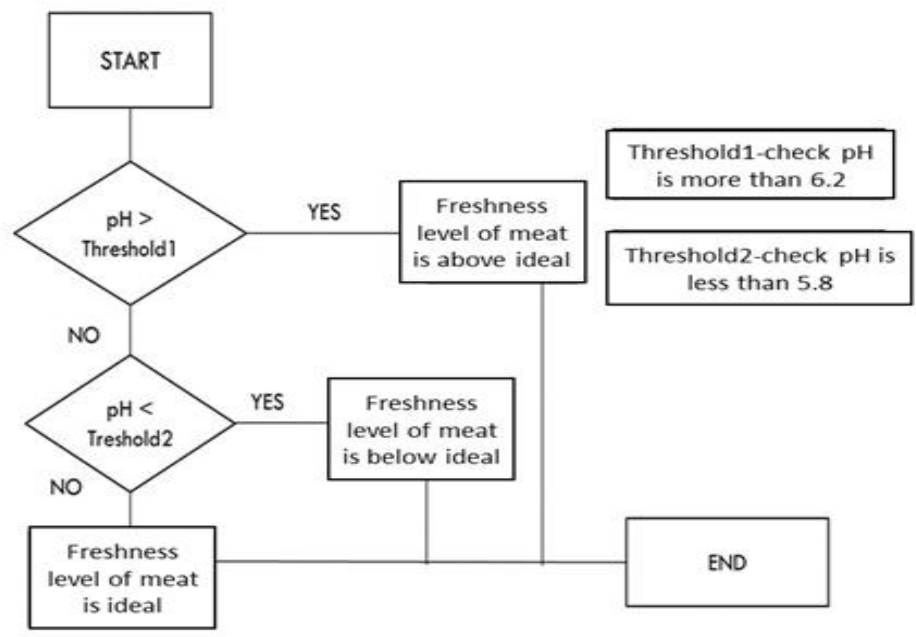

Figure 3. Flowchart of the Proposed System 


\section{SYSTEM TESTING AND VALIDATION}

To ensure the sensor operates properly, distilled water is used so the sensor result is set at 7 . We also tested the sensor capability to measure the $\mathrm{pH}$ readings accurately as shown in Table 1. Additionally, calibration is done using some $\mathrm{pH}$ buffer solutions as can be seen by Figure 4. Calibration was the challenging part in this process because of the plus and minus value of the $\mathrm{pH}$ readings.

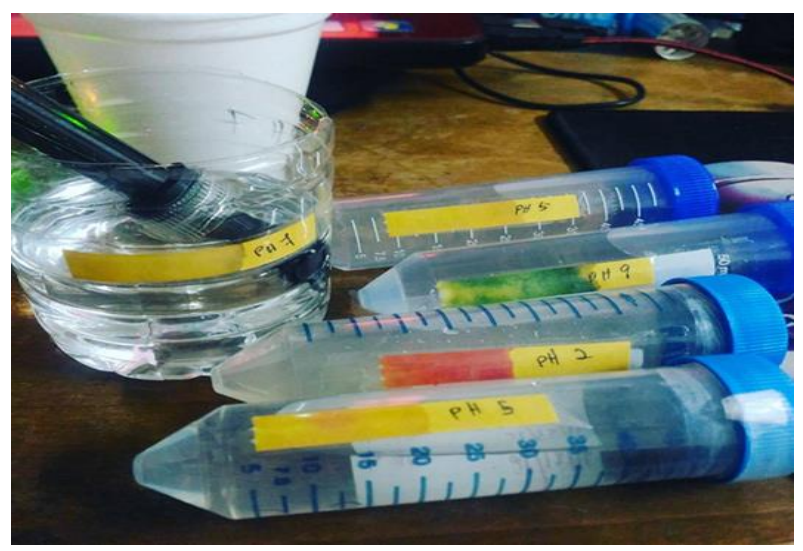

Figure 4. pH Buffer Solution

Table 1 . The result of the capability testing conducted on the setup sensors

\begin{tabular}{ll}
\hline pH Buffer solution & Result given by the Developed pH sensors \\
\hline Pure Water - $\mathrm{pH} 7$ & $\mathrm{pH} \mathrm{7}$ \\
$\mathrm{pH} 2$ solution & $\mathrm{pH} 3$ \\
$\mathrm{pH} 5$ solution & $\mathrm{pH} \mathrm{5}$ \\
$\mathrm{pH} 8$ solution & $\mathrm{pH} \mathrm{9}$ \\
$\mathrm{pH} 9$ solution & $\mathrm{pH} \mathrm{9}$ \\
\hline
\end{tabular}

To test the meat $\mathrm{pH}$ level in this research, some amount of meat, are blended and the samples are put in a container. Figure 5 and Figure 6 show the sample of meat that to be blended. Sensor is soaked in the sample to get the $\mathrm{pH}$ readings displayed on the LCD screen as depicted by Figure 7.

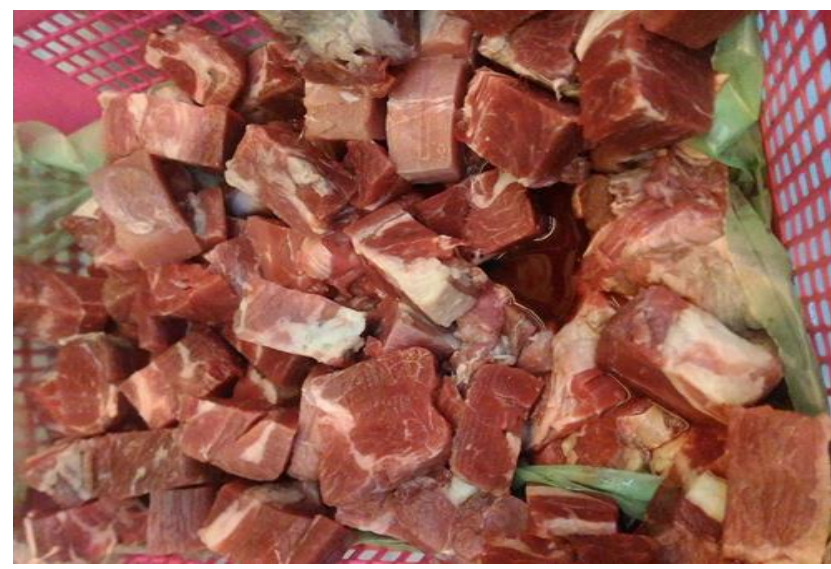

Figure 5. Meat Sample for the testing 


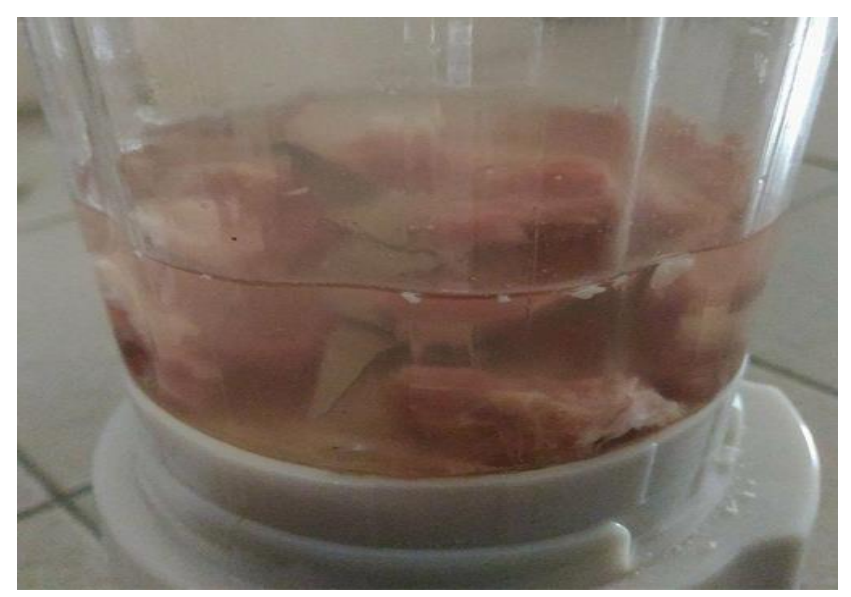

Figure 6. Meat Sample to be blended

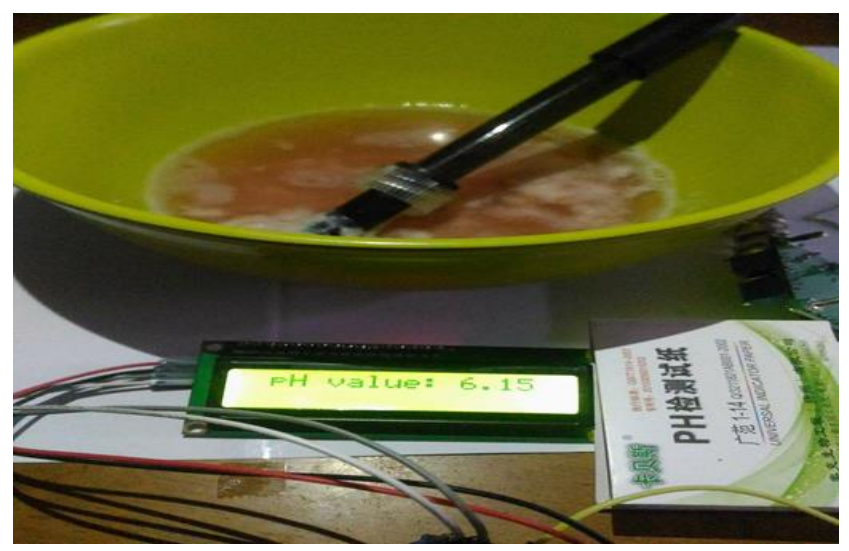

Figure 7. The blended meat with the pH sensor and LCD

Testing is done on variety of meat to see the meat freshness value either it is fresh, ideal, or spoiled. The fresh meat bought from the Kajang fresh market is categorized into 3 portions. All the 3 portions are left at room temperature and at a temperature more than 35 degree Celsius, with varying hours whereby, one portion is left for 2 hours, while another one portion is left at 4 hours and the last portion is left at 12 hour.

\section{RESULT AND DISCUSSION}

Through some testing and observation, the reading meat condition based on acidity level is obtained as shown in Table 2 and Table 3.

Table 2. Reading at a room temperature - between $8-10$ a.m

\begin{tabular}{lllll}
\hline 2 hours & 4 hours & 12 hours & 16 hours & 24 hours \\
\hline Ideal & Less ideal & Less acidic & Acidic & Very acidic \\
\hline
\end{tabular}

Table 3. Reading at a temperature of 35 degree Celsius

\begin{tabular}{lllll}
\hline 2 hours & 4 hours & 12 hours & 16 hours & 24 hours \\
\hline Ideal & Less ideal & acidic & More acidic & Very acidic \\
\hline
\end{tabular}

Table 2 shows the results of the reading of acidity to the meat obtained that is placed in room temperature in the morning with a different number of hours. While Table 3 , is the result of reading the acidity of the meat that is also placed in room temperature but after 12 o'clock. 


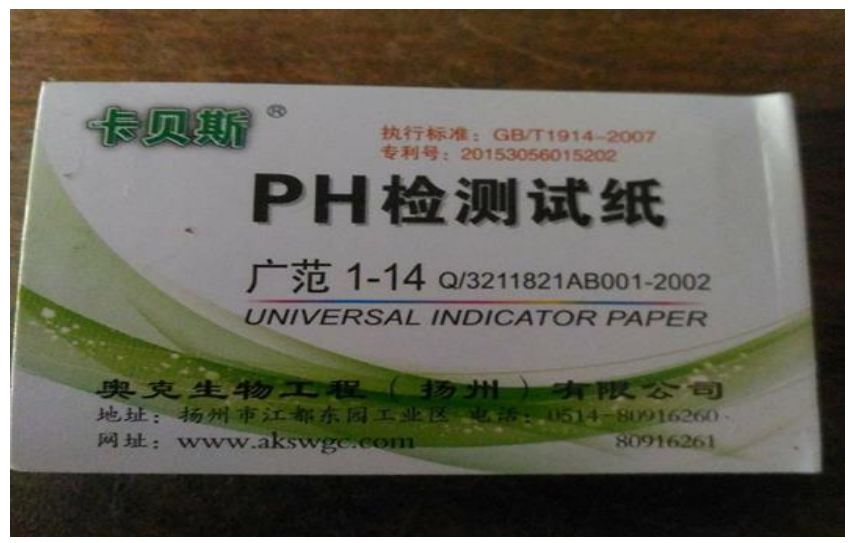

Figure 8. Commercial $\mathrm{pH}$ paper for meat validation testing

In both decisions, different acidity levels for both the situation, i.e. in the same number of hours, the meat can become acidic easily at high temperatures compared to the one at the lower temperatures. This means, at a high ambient temperature, the freshness of the meat will be easily reduced.

Validation is done by testing the product with $\mathrm{pH}$ paper as referring to Figure 8, the readings from $\mathrm{pH}$ sensor are round figures without any decimal. Besides validating using $\mathrm{pH}$ papers, sensory evaluation was also conducted. For this preliminary study, the sensory evaluation panels are done among the UNITEN staffs. Sensory evaluation result obtained as tabulated by Table 4 . Hence, the prototype developed can be used as a base study for more detail and comprehensive food freshness level.

Table 4. Sensory Evaluation Result

\begin{tabular}{llllll}
\hline & 1 Hours & 2 Hours & 6 Hours & 12 Hours & 16 Hours \\
\hline $\begin{array}{l}\text { Reading by the Developed } \\
\text { Sensors }\end{array}$ & Ideal 5.7 & Almost ideal & Acidic & Acidic & Very acidic \\
& & 5.4 & 4.5 & 4.2 & 3 \\
$\begin{array}{l}\text { Reading by the commercial pH } \\
\text { Sensors }\end{array}$ & 5 & 5 & 4 & 4 & 3 \\
Sensory Evaluation & $\begin{array}{l}\text { No peculiar } \\
\text { smell } \\
\text { (fresh) }\end{array}$ & $\begin{array}{l}\text { No peculiar } \\
\text { smell (fresh) }\end{array}$ & $\begin{array}{l}\text { Light peculiar } \\
\text { smell } \\
\text { (Less fresh) }\end{array}$ & $\begin{array}{l}\text { Foul } \\
\text { (Not Fresh) }\end{array}$ & $\begin{array}{l}\text { Stink } \\
\text { (Not fresh) }\end{array}$ \\
\hline
\end{tabular}

Test was also conducted to measure sample reactions and response time. The pH sensor responded less than 4.24 seconds for test conducted more than 20 times as shown in Table 5. Table 5 summarizes sensor response on only for the first 10 sequence of runs. The $\mathrm{pH}$ sensor test is also done on lean meat, however, the sensor is not showing any response. This shows the limitation of the research as the sensor only functions for liquid-based specimen paper as referring to Figure 8, the readings from $\mathrm{pH}$ sensor are round figures without any decimal.

Besides validating using $\mathrm{pH}$ papers, sensory evaluation was also conducted. For this preliminary study, the sensory evaluation panels are done among the UNITEN staffs. Sensory evaluation result as tabulated by Table 4 . Hence, the prototype developed can be used as a base study for more detail and comprehensive food freshness level.

Test was also conducted to measure sample reactions and response time calculated as Response Time $=\mathrm{T}_{\text {Data-received }}-\mathrm{T}_{\text {Request-sent }}$ where $\mathrm{T}$ is time. The $\mathrm{pH}$ sensor responded less than 4.24 seconds for test conducted more than 20 times as shown in Table 5. Table 5 summarizes sensor response on only for the first 10 sequence of runs. The $\mathrm{pH}$ sensor test is also done on lean meat, however, the sensor is not showing any response as shown in Figure 9. This shows the limitation of the research as the sensor only functions for liquid-based specimen. 
Table 5. Response Time from the $\mathrm{pH}$ sensors towards type of meat

\begin{tabular}{cll}
\hline $\begin{array}{c}\text { Number of } \\
\text { Runs }\end{array}$ & $\begin{array}{l}\text { Sensor's Response (in Seconds) } \\
\text { Lean Meat }\end{array}$ & Blended meat \\
\hline 1 & NO Respond (0) & 3.98 \\
2 & NO Respond (0) & 3.99 \\
3 & NO Respond (0) & 3.7 \\
4 & NO Respond (0) & 3.6 \\
5 & NO Respond (0) & 3.9 \\
6 & NO Respond (0) & 3.8 \\
7 & NO Respond (0) & 3.96 \\
8 & NO Respond (0) & 3.7 \\
9 & NO Respond (0) & 3.9 \\
10 & NO Respond (0) & 3.9 \\
\hline
\end{tabular}

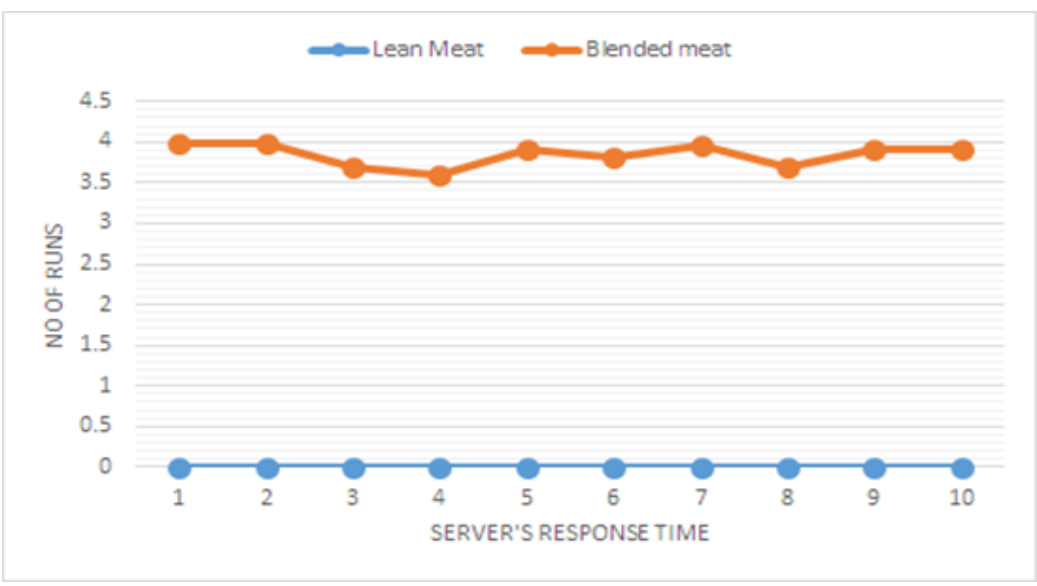

Figure 9. Time of Response of Lean Meat and Blended Meat

This small number of response time might be accepted by home consumers; however, at a larger scale in terms of meat packaging and grading, this response time need to be improved further to expedite the process. Slower response can degrade the meat quality.

\section{CONCLUSION}

In this paper, raw meat freshness level using $\mathrm{pH}$ sensor has been developed and tested on some amount of meat sample bought from the local fresh market. Test has also been conducted on sensor capability reacting with several buffer solutions on meat samples left at room temperature at various periods of time. Generally, the embedded $\mathrm{pH}$ sensor developed has successfully tested raw meat freshness level based on meat acidity level. However, further research is needed to test bigger sample size with varying condition of meat storage.

\section{ACKNOWLEDGEMENTS} Abidin.

This research is partially funded by University Tenaga Nasional, and Universiti Sultan Zainal

\section{REFERENCES}

[1] C Rukchon, A Nopwinyuwong, S Trevanich, T Jinkaran, P Suppakul. Development of a food spoilage indicator for monitoring freshness of skinless chicken breast. Talanta. 2014; 130:547-554.

[2] World Health Organization. Global burden of foodborne diseases. Media Release. http://www.who.int/mediacentre/news/releases/2015/foodborne-disease-estimates/en/

[3] K Eom, K Hyun, S Lin, J Kim. The Meat Freshness Monitoring System Using the Smart RFID Tag. International Journal of Distributed Sensor Networks. Volume 2014, Article ID 591812, 9 pages.

[4] M Mamat, S A Samad, M A Hannan. An Electronic Nose for Reliable Measurement and Correct Classification of Beverages. Sensors. 2011; 11(6):6435-6453. 
[5] S G Sharma. Implementation of Artificial Neural Network for odor Identification using E-Nose. National Conference on Computational Instrumentation (NCCI 2010). Chandigarh, India, 19-20 March 2010.

[6] L Pan, S X Yang. An Electronic Nose Network System for Online Monitoring of Livestock Farm Odors. IEEE/ASME Transactions on Mechatronics. 2009; 14(3):371-376.

[7] I A Casalinuovo, D D Pierro, M Coletta, P D Francesco. Application of Electronic Nose for Disease Diagnosis and Food Spoilage Detection. Sensors. 2006; 6(11): 1428-1439.

[8] W Woraprayotea, Y Malilaa, S Sorapukdeeb, A Swetwiwathanac, S Benjakuld, W Visessanguan. Bacteriocins from lactic acid bacteria and their applications in meat and meat products. Meat Science. 2016; 120:118-132.

[9] A Węglarz. Meat quality defined based on $\mathrm{pH}$ and colour depending on cattle category and slaughter season. Czech J. Anim. Sci. 2010; 55(12): 548-556.

[10] V Muchenje, K Dzama, M Chimonyo, P E Strydom, A Hugo, J G Raats. Some biochemical aspects pertaining to beef eating quality and consumer health: A review. Food Chemistry. 2009; 112:279-289.

[11] D M Wulf, S F O'Connor, J D Tatum, G C Smith. Using objective measures of muscle color to predict beef longissimus tenderness. Journal of Animal Science. 1997; 75:684-692.

[12] D M Wulf, J W Wise. Measuring muscle color on beef carcasses using the $\mathrm{L} * \mathrm{a} * \mathrm{~b} *$ color space. Journal of Animal Science. 1999; 77: 2418-2427.

[13] J K Page, D M Wulf, T R Schwotzer. A survey of beef muscle color and pH. Journal of Animal Science. 2001:79: 678-687.

[14] B Kuswandi, F Damayanti, Jayus, A Abdullah, L Y Heng. Simple and Low-Cost On-Package Sticker Sensor based on Litmus Paper for Real-Time Monitoring of Beef Freshness. J. Math. Fund. Sci. 2015; 47(3): 236-251.

[15] Oakton Tech Tips. Available at http://www.4oakton.Ocom/TechTips/OAK_TT06.pdf.

[16] pH meter. Omics International. Avalable at http://research.omicsgroup.org/index.php/PH_meter\#cite_note-1. 